\title{
Frequency response modelling of maritime pine (Pinus pinaster L.) wood at low frequencies
}

\author{
A. Hakam ${ }^{1}$, N. El Imame ${ }^{1}$ \\ 1. Wood Science Laboratory, Mohammed V University in Rabat, Faculty of Science, PO Box 1014, Rabat, Morocco
}

Received 14 May 2017,
Revised 10 Jul 2017,
Accepted 13 Jul 2017
Keywords
$\checkmark \quad$ Wood;
$\checkmark \quad$ Maritime pine;
$\checkmark \quad$ Electrical Impedance
$\quad$ Spectroscopy (EIS);
$\checkmark$ Modelling;
$\checkmark$ Double-DCE model
$\quad$ A Hakam
$\frac{\text { ahakam@fsr.ac.ma }}{\mathbf{+ 2 1 2 6 6 1 2 0 0 2 4 6}}$

\begin{abstract}
Maritime pine (Pinus pinaster var. atlantica) wood (MPW) of western Mamora forest was characterized by electrical impedance spectroscopy (EIS) measurements at room temperature $\left(20 \pm 2{ }^{\circ} \mathrm{C}\right)$ and under frequency interval of $40 \mathrm{~Hz}-100 \mathrm{KHz}$. One of the main applications of the SIE is the study of the fundamental electrical properties of materials in order to correlate them with the intrinsic characteristics of the latter. The double-DCE (ZARC) model was used as equivalent circuit for the MPW. The electrical impedance parameters of this model such as intracellular resistance $(\mathrm{Ri})$, extracellular resistances $\left(\mathrm{Re}_{1}\right.$ and $\operatorname{Re}_{2}$ ), relaxation time ( $\tau_{1}$ and $\tau_{2}$ ) and the distributed coefficient of the relaxation time $\left(\Psi_{1}\right.$ and $\left.\Psi_{2}\right)$ for the MPW specimens were determined.
\end{abstract}

\section{Introduction}

The forest area in Morocco is estimated at 5.8 Mha 12000 ha is for pine trees (pinus pinaster) [1]. The maritime pine is a species of the western Mediterranean with an Atlantic affinity. It is predominantly widespread in the western basin of the Mediterranean. He spontaneously grows in Morocco, Algeria, Corsica, France and Tunisia. Outside these areas, maritime pine is also found in Italy, Portugal and south-western Spain [2]. On the other hand Electrical impedance spectroscopy (EIS) is one of the potential methods for non-destructive analysis for assessment of wood moisture content [3,4], moisture gradient, mould development [5], detecting mycorrhizal colonisation [6], Evaluation of the Interfacial Compatibility in Wood Flour/Polypropylene Composites [7] and extractives analyses. It measures the impedance properties of a medium as a function of frequencies [8]. The effect of density on the electrical properties of wood was extensively studied by Skaar [9], Rafalski [10], Lin[11] and Vermaas [12]. Vermaas concluded that the dielectric constant $\varepsilon$ ' for all directions increased with the increase of density and moisture content, and decreased with the increased frequency. This method is known by its simplicity, rapidity and efficiency. This technique generally makes it possible to connect the results of the electrical measurements with the physical and chemical properties of the material through the frequency response modelling of the studied samples by an equivalent circuit $[13,14]$. EIS has been used to study stress reaction in plants [15-17]. The method provides information about the physicochemical properties of cellular structure. According to Tiitta et al. 1999 [18], Tiitta et al. 2003 [19] and Hakam et al. 2017 [20], EIS might be a useful technique to distinguish decayed and sound wood. The characterization of MPW with a low frequency electrical field has not yet been studied. It may provide a valuable basis for determining defects in this wood non destructively, and may help to understand wood-water interactions and hygroscopic characteristics of wood. This work consists on testing the proficiency of the EIS to examine the electrical impedance of MPW at low frequency.

\section{Experimental details}

\subsection{Materials}

The wood specimens (maritime pine, sapwood) were obtained from Forestry Research Center (CRF), Rabat (Morocco). The study was carried out on mature maritime pine trees of 45 years old at western Mamora forest $\left(6^{\circ} 45^{\prime} \mathrm{O}, 34^{\circ} 2^{\prime} \mathrm{N}, 30 \mathrm{~m}\right.$ of altitude), Rabat, Morocco. Mamora soil is made of a clay layer on which we have red 
or pink colour sand layer. The average annual precipitation is $500 \mathrm{~mm}$ and the average temperature is between 15 and $23^{\circ} \mathrm{C}$. From the felled tree a $\log$ at $3 \mathrm{~m}$ stem height was sawed into planks of $60 \mathrm{~mm}$ thickness. From sound planks, specimens for the electrical measurements were cut into square pieces of $40 \mathrm{~mm}$ and 2 to $4 \mathrm{~mm}$ of thickness in longitudinal direction to the growth ring, and gently smoothed by sanding (Figure 1). For physical measurements (moisture content and density) specimens were cut into cubic pieces of $20 \mathrm{~mm}$. All specimens were free of cracks, discoloration, biological attack, insect holes and other defects. In study wood samples was analyzed under normal laboratory conditions (Table 1) (Temperature of $20 \pm 2{ }^{\circ} \mathrm{C}$ and moisture content of 15 $\%)$.

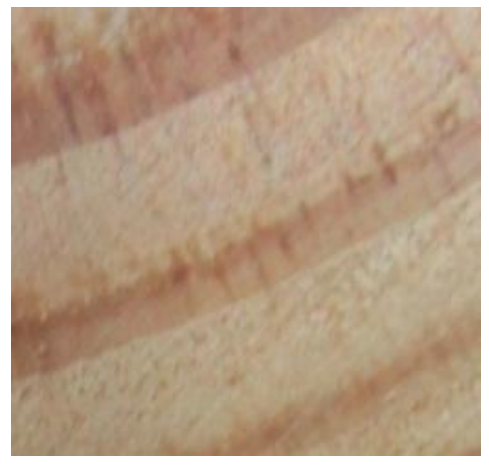

Figure 1: Contact surfaces of sample

\begin{tabular}{|l|c|c|c|c|}
\hline & Av. & Max & Min & CV (\%) \\
\hline $\mathrm{D}_{\mathrm{h}}$ & 0.650 & 0.695 & 0.491 & 7.89 \\
\hline $\mathrm{MC} \%$ & 15 & 15.4 & 14.8 & 19.64 \\
\hline
\end{tabular}

Table 1: Parameters of the investigated wood samples

Before the impedance measurements the samples were weighed and the dimensions were measured. After the impedance measurements, the specimens were dried at $103 \pm 3^{\circ} \mathrm{C}$ for $24 \mathrm{~h}$ and weighed. The dimensions, moisture content and densities were measured with $0.1 \mathrm{mg}$ accuracy in weight, and $0.02 \mathrm{~mm}$ for dimensions. All specimens were kept in the same chamber at the same ambient conditions. The moisture content (MC) of specimen was calculated with:

$$
\mathrm{MC} \%=\frac{\left(M_{H}-M_{0}\right)}{M_{0}} 100
$$

Where, $\mathrm{M}_{\mathrm{H}}$ is air-dry mass before the impedance measurements and $\mathrm{M}_{0}$ is the oven-dry mass after drying at 103 $\pm 3^{\circ} \mathrm{C}$ for $24 \mathrm{~h}$.

\subsection{Impedance measurements}

Indeed, relaxation and / or polarization of the excited materials are caused by the alternating current. The physical parameter varies with the frequency of the applied voltage; this may be due either to the physical structure of the materials or to the chemical and physical processes which occur within the subjected material. Thus, an impedance measurement over an appropriate frequency range offers the possibility of relating the measured electrical parameters to the physical and chemical properties of the materials. The EIS measurements on the MPW samples were carried out at ambient temperature with two copper circular electrodes placed directly in contact with the material without the use of conductive gel. The two electrodes were connected directly to the impedance measuring device (Hewlett-Packard LCZ-meter 3330), with a frequencies ranging from $40 \mathrm{~Hz}$ to $100 \mathrm{KHz}$.

\subsection{Electrical modelling}

It has been proved in several previous studies that the frequency response of biological tissues $[15,16,17,18$, 20] such as wood cannot be adjusted using simple elements such as resistances (R), capacitances (C), inductances (L) or diffusion impedances. This frequency dispersion is often described as a change in capacitance and is expressed in terms of Constant Phase Elements (CPE): 


$$
Z_{C P E}=\frac{1}{(i \omega C)^{\psi}}
$$

Where $\mathrm{C}$ is the capacity, $\omega$ the angular frequency, $\Psi$ the distribution coefficient of the relaxation time and $i$ the imaginary unit. In this study, the double-DCE mathematical model (ZARC) [21] which is illustrated by an equivalent scheme was fitted to the data. The DCE double model (ZARC) comprises two distributed circuit elements $(\mathrm{DCE})$ in series with a resistance $(\mathrm{R} \infty=$ very high frequency resistance) (Figure 2$)$. The DCE element includes a constant phase element $(\mathrm{CPE})$ in parallel with a resistor $(\mathrm{R})$ :

$$
Z_{D C E}=\frac{R}{1+(i \omega \tau)^{\psi}}
$$

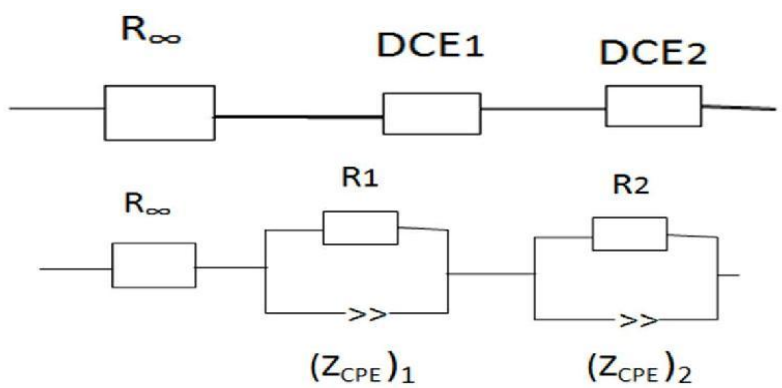

Figure 2: Equivalent circuit of the double-DCE model (ZARC)

Electrical parameters of this model were determined for MPW: intracellular resistance $\left(\mathrm{R}_{\mathrm{i}}=\mathrm{R}_{\infty}\right)$, extracellular resistances $\left(\operatorname{Re}_{1}=R_{1}\right.$ and $\left.\operatorname{Re}_{2}=R_{2}\right)$, relaxation times $\left(\tau_{1}\right.$ and $\left.\tau_{2}\right)$ and coefficients of relaxation time distribution $\left(\Psi_{1}\right.$ and $\left.\Psi_{2}\right)$. The parameters of the model were estimated using the complex non-linear least squares (CNLS) curve fitting program LEVM version 8.13 (J.R. Macdonald, Department of Physics and Astronomy, University of North Carolina, Chapel Hill, USA).

\section{Results and Discussion}

The electrical impedance spectra of MPW were measured in the laboratory in the way described above. The behaviour of the imaginary part of the impedance $\left(Z_{i}\right)$ as a function of the real part of the impedance $\left(Z_{r}\right)$ for the MPW at ambient temperature is exhibited in figures 3.

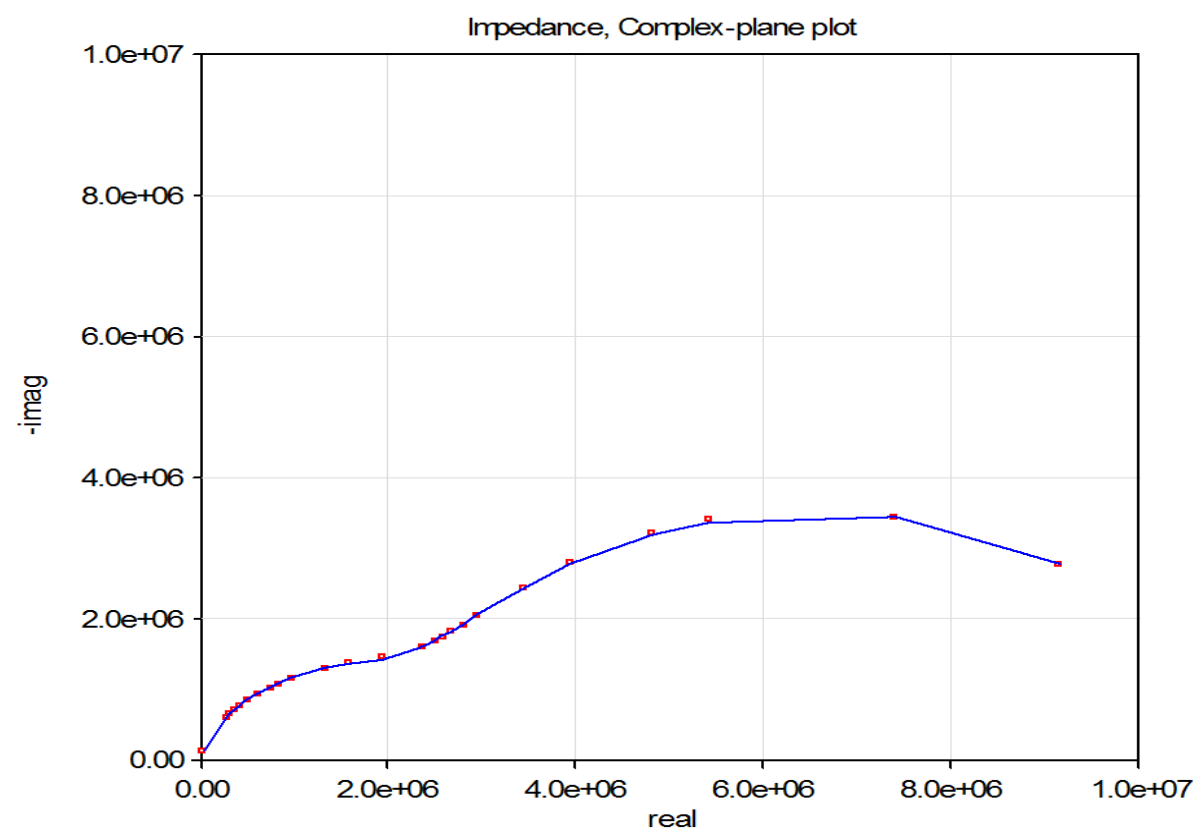

Figure 3: Examples of impedance spectra and the best fits: double $\mathrm{ZC}$ - model; $\mathrm{f}=40 \mathrm{~Hz}-100 \mathrm{KHz}$ for the MPW. Experimental (dashed) and theoretical (continuous lines) curves deduced from the double DCE model. Frequency increases from right $(40 \mathrm{~Hz})$ to left $(100 \mathrm{KHz})$ measurements 
The impedance spectrum of every sample had a double arc in the form of parabola where the top corresponds to the frequency value characteristic of material $f_{c}$ and the intersection of the parabola with the $x$ axis gives $R_{\infty}$ and the $\mathrm{R}_{\mathrm{e}}$. It is noteworthy that the experimental curves (in dotted lines) coincide perfectly with the curves (in solid lines) deduced from the double DCE model (Figure 3). The knowledge of the experimental values for each frequency of the real part of the electrical impedance $\left(Z_{\mathrm{r}}\right)$ and the imaginary part of the impedance $\left(\mathrm{Z}_{\mathrm{i}}\right)$ or the real part of the admittance $\left(\mathrm{Y}_{\mathrm{r}}\right)$ and the part $\left(\mathrm{Y}_{\mathrm{i}}\right)$ makes it possible to deduce the dielectric constant $(\varepsilon)$ and the electrical modulus (M) as a function of the frequency by a simple calculation, taking into account the geometrical parameters of the samples. Thus, the real of the dielectric constant $\left(\varepsilon^{\prime}\right)$ and the imaginary part of the dielectric constant ( $\left.\varepsilon^{\prime \prime}\right)$ for the MPW as a function of the frequency at ambient temperature is shown in Figure 4.
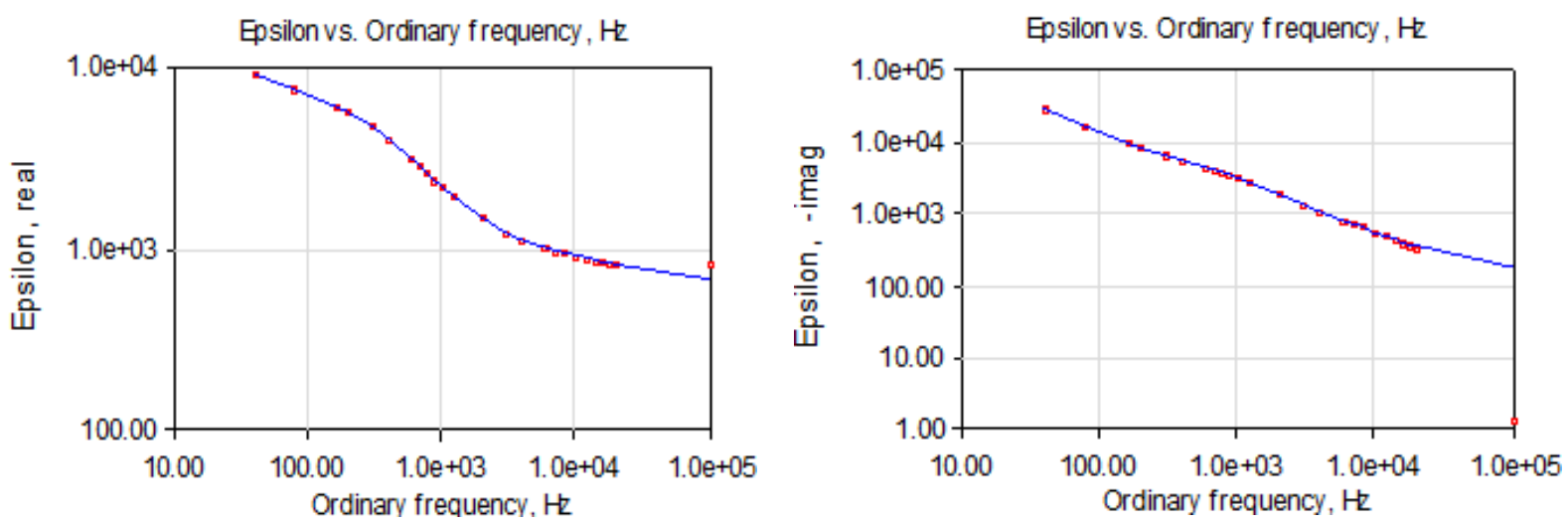

Figure 4: (a) Real component of dielectric constant $\left(\varepsilon^{\prime}\right)$ for PMW versus frequency. (b) Imaginary component of the dielectric constant $\left(\varepsilon^{\prime \prime}\right)$ for PMW depending on frequency. Experimental (dashed) and theoretical (continuous lines) curves deduced from the double DCE model

The real part of the modulus $\left(\mathrm{M}^{\prime}\right)$ and the imaginary part of the modulus ( $\left.\mathbf{M}^{\prime \prime}\right)$ for the MPW as a function of the frequency at ambient temperature is shown in Figure 5.
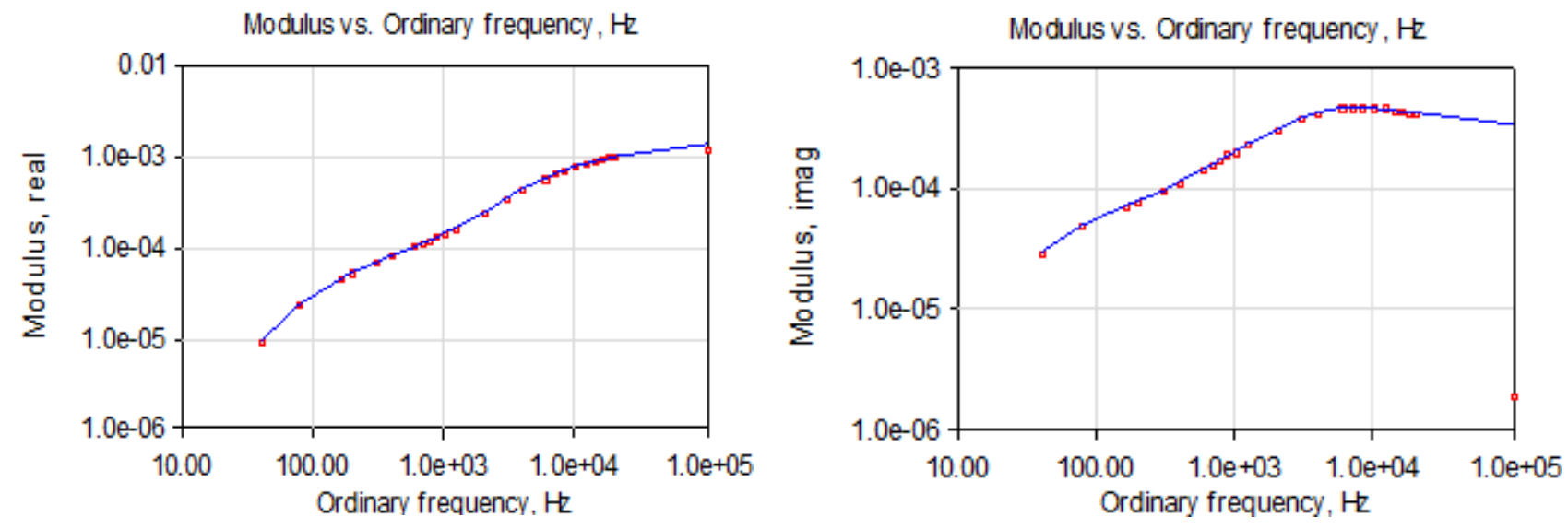

Figure 5: (a) Real component of the modulus (M') for PMW versus frequency. (b) Imaginary component of the modulus (M') for PMW versus frequency. Experimental (dashed) and theoretical (continuous lines) curves deduced from the double DCE model

The electrical parameter values from double ZC-model (fig 2) fits for the PMW specimens under normal laboratory conditions were clearly depicted in Table 2 . Parameters $\mathrm{R}_{1}, \tau_{1}$ and $\psi_{1}$ represent a higher frequency arc and $R_{2}, \tau_{2}$ and $\psi_{2}$ the low frequency arc of the spectrum. 


\begin{tabular}{|c|c|c|c|c|c|}
\hline $\mathbf{R}_{\mathbf{1}}(\mathbf{M} \boldsymbol{\Omega})$ & $\boldsymbol{\tau}_{\mathbf{1}}(\boldsymbol{\mu \mathbf { s }})$ & $\boldsymbol{\psi}_{\mathbf{1}}$ & $\mathbf{R}_{\mathbf{2}}(\mathbf{M} \boldsymbol{\Omega})$ & $\boldsymbol{\tau}_{\mathbf{2}}(\boldsymbol{\mu} \mathbf{s})$ & $\boldsymbol{\psi}_{\mathbf{2}}$ \\
\hline 2.15 & 34.8 & 0.885 & 9.14 & 1554 & 0.824 \\
\hline
\end{tabular}

Table 2: The electrical parameters from the Double-DCE (ZARC) model

\section{Conclusions}

Within this study, SIE method was used to examine the electrical properties of MPW at room temperature (20 \pm $2{ }^{\circ} \mathrm{C}$ ). The Double-DCE (ZARC) model was used as an equivalent circuit. The impedance spectra of MPW consisted of two arcs in a complex plane between 40 and $100 \mathrm{KHz}$. The experimental curves (in dotted lines) and theoretical (continuous lines) curves deduced from the double DCE model coincide perfectly. The doubleDCE model fitted the spectra well.

\section{References}

1. Mhirit O., Blerot P., Le grand livre de la forêt marocaine. Editions Mardaga. Liège, Belqique (1999) $280 \mathrm{p}$.

2. Boudy P., Economie forestière nord-africaine, monographie et traitement des essences forestières $1950.2 \mathrm{~V}$ La Rose, Paris 505 p.

3. Zelinka S.L., Stone D.S., Rammer D.R., Wood Fiber Sci. 39 (2007) 556.

4. Zelinka S.L., Douglas R. Rammer D.R., Stone D.S., Holzforschung. 62 (2008) 737.

5. Tiitta M., Tomppo L., Järnström H., Löija M., Laakso T., Harju A., Venäläinen M., Iitti H., Paajanen L., Saranpää P., Lappalainen R., Viitanen H., Eur. J. Wood Wood Prod. 67 (2009) 151.

6. Repo T., Korhonen A., Laukkanen M., Lehto T., Silvennoinen R., Biosyst Eng. 121 (2014) 139.

7. Zhu L., Cao J., Wang Y., J. Appl. Polym. Sci. 129 (2013) 1520.

8. Kremer F., Schönhals A., Broadband Dielectric Spectroscopy, Springer-Verlag (2003) 729 p.

9. Skaar C. The dielectric properties of wood at several radio frequencies. Syracuse University. New York. 1948.

10. Rafalski J. Uber die dielektrischen eigenschaften unterschiedlich verdichteten rot-buchenvollholzes. Holztechnologie. 7 (1966) 118.

11. Lin R.T. Wood as an orthrotropic dielectric material. Wood and Fiber. 5(1973) 226.

12. Vermaas H. Regression equations for determining the dielectric properties of wood. Holzforschung. 27 (1973) 132.

13. Cao Y., Repo T., Silvennoinen R., Lehto T., Pelkonen P., J Exp Bot. 62 (2011) 351.

14. Zelinka S.L., Wiedenhoeft A.C., Glass S.V., Ruffinatto F., Wood mater.sci.eng.10 (2015) 189.

15. Repo T., Zhang G., Ryyppo A., Rikala R., J Exp Bot. 51 (2000) 2095.

16. Väinölä A., Repo T., Ann. Bot. 86 (2000) 799.

17. Hakam A., Magne Takam M., Chokairi M., Alami Chantoufi N., Hamoutahra Z., El Alami A., Famiri A., Ziani M., Gril J., Maderas, Cienc. tecnol. 14 (2012) 195.

18. Tiitta M., Repo T., Viitanen H., Mater. Org. 33 (1999) 271.

19. Tiitta M., Kainulainen P., Harju A.M., Venäläinen M., Manninen M., Vuorinen M., Viitanen H., Holzforschung. 57 (2003) 433.

20. Hakam A., Alami Chantoufi N., El Imame N., Guelzim M., Ziani M., Famiri A., Drissi Bakhkhat S., Ghailane F., Hachmi M., Sesbou A., Merlin A., Int. J. Pharmacognosy and Phytochem. Res. 9 (2017) 444.

21. MacDonald J.R., Impedance Spectroscopy. John Wiley \& Sons, New York (1987) 368 p.

(2017) ; http://www.jmaterenvironsci.com 